\title{
Using Online Tests to Enhance Teaching and Learning
}

\author{
Ling Chen \\ The City University of New York \\ Borough of Manhattan Community College
}

\begin{abstract}
This article describes how online tests are used to achieve the following goals: 1) to engage and to motivate students learning chemistry; 2) to understand how students solve difficult problems; 3) to assess students learning outcomes that are listed on the course syllabus; and 4) to evaluate instructors teaching. Online testing includes online test questions and assessment questions. Both are made available on Blackboard. The online tests include chapter quizzes and review tests, two low-stake tests. Students can improve their grades as many times as they wish through the Blackboard online. Whenever mistakes are made, students are encouraged to review the course material, and to re-solve the problems. For each online test it normally takes a student three attempts to fix his or her mistakes. From these activities, students learn to be accountable for their performance and to use resources effectively. From the Grade Center instructors can View Grade Details and understand how students have handled difficult concepts. For the course assessment, however, only one attempt is allowed. The results of the assessment indicate $33 \%$ of the students have troubles distinguishing exothermic and endothermic reactions. Online testing is an innovative and effective pedagogical tool that not only bonds students and instructors; but also balances the instructors' guidance and students' efforts.
\end{abstract}

Key words: online tests, e-learning, engage, motivate, guide, assessment

\section{INTRODUCTION}

In conventional teaching, information flows from instructors to students and is often culminates with examinations. In class, even though instructors review concepts and solve problems methodically, their efforts are limited by the class time and student-attention span. After class, the influence of the instructors becomes even more remote and less effective.
According to The Condition of College \& Career Readiness 2011 [1], in the United States, many urban high school graduates never learned how to study sciences and do not have the necessary skills for success in colleges. Student learning is passive and knowledge retention can be poor.

Furthermore, many students at BMCC work full- time, raise families, and juggle other responsibilities. The reality of balancing work, school, and family lives takes a big toll on them both physically and mentally. Oftentimes, students can hardly keep up with the lecture pace and easily become lost in their studies.

To better suit student work and life schedules, some science lectures are designed to last three hours (or six hours with labs). During such long hours of class, students are likely to be in a passive mode of merely listening to the lecturer. They often promise to catch up on their own or to seek help from tutors, but that seldom happens either due to lack of time, motivation or both. After the dreaded exams, most students normally do not bother to revisit the mistakes made on the test even if they do not do well. Some difficult concepts never get another look; and the cycle repeats itself from semester to semester.

Instructors who are eager to put a stop to the cycle often wonder about the following questions:

1. How can information be broken into smaller pieces to fit into students' busy lifestyles?

2. What methods can guide students to use resources more effectively?

3. How can students be encouraged to apply knowledge they learned to solve problems on their own?

4. What are the best ways to assess learning so that teaching can be improved?

Technology can offer potential solutions to the dilemmas encountered by both instructors and students. Technology is a regular presence in our daily lives; it makes 
communication and collaboration possible around the clock. Internet is second nature to most students and they have already enjoyed it in many aspects of their lives. In addition, e-Learning plays an important role in 21 stcentury, making students more competitive in their prospective fields.

Educators should make the use of technology such as the Internet to benefit students learning and to accommodate their various needs. Distance learning or e-learning, for example, can offer instructors some advantages by breaking course materials down into smaller pieces and delivering them over a period of time as opposed to in a single setting as in a traditional face-to-face class. Students can work at their own pace with the help and support from instructors anywhere and at anytime.

Although e-learning has gained popularity, there are some reservations about online science courses. Some instructors may feel less in control of the progress of students' learning and students may worry about lack of personalized attention. With good design and organization, online science learning can be robust, content-rich, and rewarding that benefits both e-learners and e-teachers [2].

\section{Hybrid Course Overview}

Like traditional in-person chemistry classes, my hybrid class starts with 20 to 25 students. The course integrates online and face-to-face components. The lectures are conducted online, while labs and exams are held at the college.

Lectures include 1) reading assignments (e.g. PowerPoint lecture notes, learning check questions, chapter summaries with provided web links) and 2) online submitted assignments, (e.g. discussion board, quizzes, and review tests). The class meets once a week in-person at the college for hands-on, experimental labs and high-stake formal exams.

To better organize and guide student's e-learning, a detailed study schedule that promotes the distributed-daily learning is provided at the beginning of the course. The study schedule serves as a daily planner allowing students to keep track of their progress.

Before joining in the online discussion board, students are required to prepare themselves by studying the lecture notes, solving learning-check questions and reviewing the chapter summary and web links. Students must submit a quiz for each chapter and complete a test review before every exam. Both the chapter quizzes and test reviews are low-stakes online tests that can be improved unlimited numbers of times. High-stakes exams are held in the classrooms.

\section{Method}

The title of the course is Fundamentals of General, Organic, and Biological Chemistry. The first of a two-semester course sequence introduces principles and concepts of general, organic and biological chemistry. Most students are nursing and allied health science majors. All course materials including online tests are implemented on Blackboard 9.1. The online tests include chapter quizzes, review tests and course assessment questions. All are multiple-choice questions.

Test Bank of Pearson TestGen 7 is used to generate multiple-choice questions as a test file. After opening one of the tests, under File, click Export, then select Export Exam To Blackboard 6x-9x, and name the question pool. The test questions can then be saved as a zip.file that is compatible with Blackboard 9.1. In Blackboard Control Panel of the course, first find Course Tools, then Tests, Surveys, and Pools, after which select Pools, then Import Pool. Next attach the zip.file via Browse My Computer. The zip.file is now made available in the Pool area of the course. Last find Assessments tab in Course Materials, click the following buttons in order: Tests, Create, Reuse Questions, Find Questions, Pools, and Submit. The pool questions can then be deployed to different areas of Course Materials such as chapter folders, test reviews, or assessment.

There are total of 12 quizzes in one semester. Two of the lowest quiz grades will be dropped, the remaining 10 quizzes count for 5\% of the grade. Quizzes are due at the end of each chapter. There are five review tests that count for $10 \%$ of the grade. Review tests are submitted before the face-to-face exams. Each test has about 20 questions.

After each online test submission, student work is marked and a grade is recorded automatically in grade book on Blackboard. Before the pre-set deadlines students have unlimited opportunities to improve their grades. From the Grade Center, students work history can be seen via View Grade Details and the patterns of their mistakes can be analyzed.

In addition to quizzes and practice tests for my own classes, as a course coordinator I am in charge of the course assessment, which is made available at the Blackboard and given at the end of each semester for different sections of students. There are more than 20 sections in each semester. The course assessment consists of five questions that cover some aspects of the students learning outcomes of the syllabus. The questions have been modified from semester to semester according to the results from prior semesters. 
For the assessment questions students can only submit their answers once. Using Item Analysis feature in Blackboard, the student distributions for each question can be viewed. The results of 125 students from nine different sections, taught by four different instructors are pooled and evaluated.

\section{Results}

On average, it took a student three or four attempts to obtain a perfect score. The work process is shown in Table 1 .

Table 1. Grade history shows the improvement of a student's grades in three submissions.

\begin{tabular}{|l|l|l|}
\hline Date Created & Date Submitted & Value \\
\hline $\begin{array}{l}\text { Jun 1, 2015 } \\
\text { 9:16:05 PM }\end{array}$ & $\begin{array}{l}\text { Jun 1, 2015 } \\
9: 23: 23 \text { PM }\end{array}$ & 100.00 \\
\hline $\begin{array}{l}\text { May 29, 2015 } \\
\text { 10:57:52 AM }\end{array}$ & $\begin{array}{l}\text { May 29, 2015 } \\
11: 06: 29 \text { AM }\end{array}$ & 93.00 \\
\hline $\begin{array}{l}\text { May 28, 2015 } \\
\text { 10: 35: 21 PM }\end{array}$ & $\begin{array}{l}\text { May 28, 2015 } \\
10: 57: 18 \text { PM }\end{array}$ & 79.00 \\
\hline
\end{tabular}

This student has spent three days to fix the wrong answers on one of the online tests. The grade is improved from 79 to 93 , and at last to 100 .

From Blackboard, instructors can see student's wrong answers via View Grade Details. An example follows below.

Question: Which of the following describes the reaction shown in the diagram.

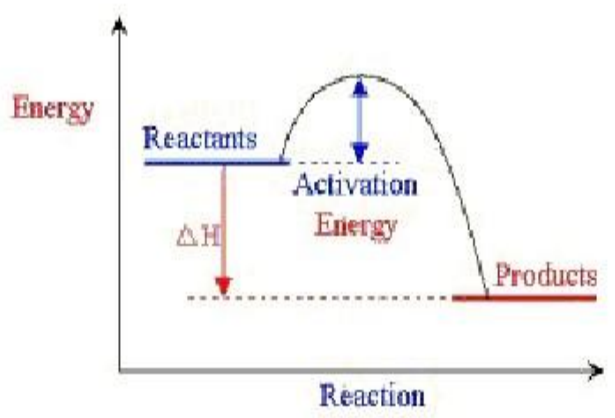

\begin{tabular}{|l|c|}
\hline $\begin{array}{l}\text { Given } \\
\text { Answer: }\end{array}$ & It's an endothermic reaction. \\
\hline $\begin{array}{l}\text { Correct } \\
\text { Answer: }\end{array}$ & It's an exothermic reaction. \\
\hline
\end{tabular}

After submission students get a feedback of which question is wrong without the correct answer being disclosed (a choice of the instructors).
Using Item Analysis feature instructors can examine the overall performance of the class, broken down in numbers (and percentages) for each answer in Table 2. Answer D is the correct answer.

Table 2. The distribution of students for the following question.

\begin{tabular}{|l|l|}
\hline \multicolumn{2}{|l|}{$\begin{array}{l}\text { Question: All of the following statements } \\
\text { concerning saturated fats are true except }\end{array}$} \\
\hline Answers & Number (\%) \\
\hline $\begin{array}{l}\text { A). They are more common in } \\
\text { animals than in plants. }\end{array}$ & $1(6.67 \%)$ \\
\hline $\begin{array}{l}\text { B). They contain more } \\
\text { hydrogen than unsaturated fats } \\
\text { having the same number of } \\
\text { carbon atoms. }\end{array}$ & $1(6.67 \%)$ \\
\hline $\begin{array}{l}\text { C). They generally solidify at } \\
\text { room temperature. }\end{array}$ & $2(13.34 \%)$ \\
\hline $\begin{array}{l}\text { D). They have multiple double } \\
\text { bonds in the carbon chains of } \\
\text { their fatty acids. }\end{array}$ & $11(73.34 \%)$ \\
\hline
\end{tabular}

Online test is also used as a valuable tool for general course assessment. In spring 2015 the assessment questions were given to nine different sections of the course taught by four different instructors. The results of 125 students were pooled together and tabulated in Table 3.

Table 3. The assessment results of students learning outcomes.

\begin{tabular}{|l|l|}
\hline Questions & $\begin{array}{l}\text { Right } \\
\text { Answers }\end{array}$ \\
\hline $\begin{array}{l}\text { 1.Which of the following is not an } \\
\text { element? }\end{array}$ & $90 \%$ \\
\hline $\begin{array}{l}\text { 2. Which of the following is NOT } \\
\text { typical of most organic } \\
\text { compounds? }\end{array}$ & $82 \%$ \\
\hline $\begin{array}{l}\text { 3. What type of bond must be } \\
\text { broken for water to vaporize? }\end{array}$ & $86 \%$ \\
\hline $\begin{array}{l}\text { 4. Ionic bond is found in which of } \\
\text { the following compound? }\end{array}$ & $76 \%$ \\
\hline $\begin{array}{l}\text { 5. Which of the following } \\
\text { describes the reaction shown in the } \\
\text { diagram? }\end{array}$ & $67 \%$ \\
\hline
\end{tabular}


The first four questions are satisfactory since $90 \%, 82 \%$, $86 \%$ and $76 \%$ of the students answered them correctly. There will be no need to assess them next semester. The last question, however, needs improvement. Only $67 \%$ students answered it correctly.

\section{Significance}

Online tests foster guided student participation and selfassessment, contrasted with aimlessly surfing for information without the needed feedback. It encourages students to think critically and to apply the knowledge to solve problems. Normally students see tests as a punishment and mistakes as failures. Online tests, however, serve them as a learning tool to enhance deeper understanding through repetitions of course material reviews. Mistakes are turned into learning opportunities. Students are actively engaged in learning while trying to fix the mistakes.

\subsection{Online Test is a Learner-Centered Activity}

Online tests are valuable tools, both pedagogical and technological, which is designed catering to different student learning styles and to provide a structured and yet student-driven learning environment. Students can study at their own pace by utilizing the online resources effectively and to be accountable for their performance.

On the contrary traditional education is teacher-centered; in which instructors are busy covering the contents listed in the syllabus without spending much time dealing with the needs of students, for example, multiple practices and reflections upon what have been learned.

The focus of the e-learning is on the learner, not the teacher. In e-learning environment, teachers become mentors and guides rather than the "all knowing" authority [3] often associated with the traditional face-to-face teaching format. Online test is a self-paced activity that accommodates to individual student's time and lifestyle. Online tests induce student behaviors that lead to meaningful learning gains; train students to "think about their thinking" during learning, and promote high levels of learning and achievement via problem solving.

\subsection{Online Tests Motivate and Assess Students Learning}

In addition to academic achievement, online tests can reduce anxiety and improve motivation. Self-assessment and self-adjustment are at the heart of better performance. Students are driven by the desire for better grades; thus online tests can engage, support and motivate student learning.
Furthermore, online tests facilitate immediate feedback. Whenever they get a question wrong, students are encouraged to re-visit the course materials and correct the mistakes as many times as they need. As mentioned in Wang, et al. [4] the online evaluation system serves as a double driving force that enable students to go back to study. Students have total control of their grades in both categories and use these tests as ways to gain knowledge and critical thinking skills. This approach gives the students many chances to grasp the information; it also balances student self-directed study and instructors' attentive guidance. Instructors can obtain valuable information about the challenges that students encounter. This creates opportunities for instructor's reflection and connection.

By tracking down students work from multiple submissions, researchers can look at chemistry concepts through lens of students': 1) to investigate the way students think and 2) to steer clear the path for students.

\subsection{Online Tests Reflect on Teaching}

Testing is a part of American education that everyone has to face. But tests do not have to be the end of learning or punishment for students. Besides the benefits to students mentioned early in this article, there is a wealth of information for instructors so that they can reflect on their teaching and to close any loops.

Blackboard provides instructors the tools to collect and analyze data at fingertips. From the analytic results, instructors can strategize their teaching and focus on the challenges that have been identified. This closely bonds students learning with teachers teaching.

From the results of spring 2015 assessments, the top four questions in Table 3 are satisfactory. More than $76 \%$ of students answered the questions correctly. There will be no need to assess those questions again. However there are only $67 \%$ of students got the last question right. Next semester new teaching strategies will be needed to improve the performance so that the same mistakes will not be repeated again.

\section{CONCLUSIONS}

The true scenario described turns dreaded examination into best practices for teaching and learning. In this article, online testing integrates the web-based technology into the course and is used as a tool with many pedagogical features: 1) to fit students on-the-go lifestyles with flexibility of the Internet access, 2) to guide and motivate students to invest time and effort in their studies, 3) to assess student learning, 4) to advance students problemsolving skills, and 5) to enable instructors better understand the student learning so that their teaching can 
be improved. Online testing is an innovative and effective pedagogical tool that improves teaching and student learning outcomes through the effective use of technology, bonds students and instructors, and balances the instructor's guidance and student's efforts.

\section{References}

[1] 2011 National and State Scores. The Condition of College \& Career Readiness 2011. http://www.act.org/research/policymakers/cccr11/pdf/C onditionofCollegeandCareerReadiness2011.pdf

[2] Rebecca Carver, Robert King, Wallace Hannum and Brady Fowler. Toward a Model of Experiential E-
Learning. Journal of Online Learning and Teaching. Vol. 3, No. 3, September 2007.

[3] Strait, J., and Sauer, T. 2004. "Constructing Experiential Learning for Online Courses: the Birth of E-Service." EducauseQuarterly 1 November 2004. www.educause.edu/library/eqm04110

[4] Wang, X., Wang, L., and Li, D. 2013. "Construction of the Online Test System for Common Basic Course in College." Internal Conference on Advanced Information and Communication Technology for Education. ICAICTE 2013, pp146-149. ISBN (on-line): 978-90786-77-79-6 http://www.atlantispress.com/php/pub.php? publication=icaicte-13 